\title{
Three-Dimensional Navier-Stokes Simulation of Space Shuttle Main Propulsion 17-Inch Disconnect Valves
}

\author{
M. Kandula* and D. G. Pearce $\dagger$ \\ Lockheed Engineering and Sciences Company, Houston, Texas 77058
}

\begin{abstract}
A steady incompressible three-dimensional viscous flow analysis has been conducted for the Space Shuttle external tank/orbiter propellant feed line disconnect flapper valves with upstream elbows. The Navier-Stokes code, INS3D, is modified to handle interior obstacles and a simple turbulence model. The flow solver is tested for stability and convergence in the presence of interior flappers. An under-relaxation scheme has been incorporated to improve the solution stability. Important flow characteristics such as secondary flows, recirculation, vortex and wake regions, and separated flows are observed. Computed values for forces, moments, and pressure drop are in satisfactory agreement with water flow test data covering a maximum tube Reynolds number of $3.5 \times 10^{6}$. The predicted hydrodynamic stability of the flappers correlates well with the measurements.
\end{abstract}

\section{Introduction}

Q UICK separable disconnect valves are placed in the Space Shuttle main propulsion system propellant feed lines (liquid oxygen, $\mathrm{LO}_{2}$; liquid hydrogen, $\mathrm{LH}_{2}$ ) at the external tank (ET) to orbiter (ORB) interface. Each disconnect is comprised of two bolted circular tube sections, one on the ET side and the other on ORB side, with each section containing a rotary flapper valve that is operated by a pneumatic actuator on the orbiter side. Figures $1 \mathrm{a}$ and $1 \mathrm{~b}$ show the configurations of the $\mathrm{LO}_{2}$ and $\mathrm{LH}_{2}$ disconnects, respectively. A linkage exists between the actuator and the drive and follower arms attached to the flappers. The flappers are held initially by the drive arm at different angles of attack to the main flow leaving the upstream elbows. Once the flow is started, the flappers move due to flow loads and the elasticity of the linkage and settle to equilibrium positions at steady flow, as indicated by a kinematic model of the mechanism. Unsteadines's of turbulence causes the flappers to vibrate about an equilibrium position in steady state. One of the main design requirements is the flapper stability in the open position so that the flappers do not close during flow. Other design considerations include cavitation margin and pressure drop across the valve.

Extensive experimental data on the disconnects from ground tests with simulated water flow have suggested that over a certain range of flapper angle orientations the lift forces in the direction of opening begin to decrease above a certain flow rate. Such a reduction in lift force can lead to the closing of the flappers during flight, which can be catastrophic to the mission and crew safety. The reduction in lift force does not have to be accompanied by a mechanical fắilure of the drive/follower arms in order for the valve to close. A detailed computational fluid dynamics (CFD) analysis of the complex flow around the flappers is therefore important for improved design and specification of stable flapper orientations.

Incompressible three-dimensional Navier-Stokes simulation of fluid flow has thus regained increased attention in recent years in view of its application to propulsion systems such as described previously. Although several three-dimensional codes are developed for compressible flows (e.g., Refs. 1 and 2 ), very few solution codes are presently available for the

Received Feb. 21, 1989; revision received Feb. 5, 1990. Copyright (C) 1990 by the American Institute of Aeronautics and Astronautics, Inc. No copyright is asserted in the United States under Title 17, U.S. Code. The U.S. Government häs a royalty-free license to exercise all rights under the copyright claimed herein for Governmental purposes. All other rights are reserved by the copyright owner.

*Advanced Systems Engineering Specialist. Member AIAA.

†Senior Engineer. Member AIAA. analysis of incompressible flow. The problem of pressurevelocity coupling in incompressible flow is generally addressed by Poisson equation for pressure, ${ }^{3}$ vorticity-velocity formulation, ${ }^{4,5}$ pressure-correction equation, ${ }^{6}$ or artificial compressibility. ${ }^{7-9}$

Although not time accurate, the method of artificial compressibility generates a hyperbolic system of equations in primitive variables that can be solved conveniently for steady flows in generalized curvilinear coordinates. Kwak et al. ${ }^{9}$ have recently developed a Navier-Stokes code, INS3D, to solve incompressible flow equations using this method. This code is tested for internal and external flows and in laminar and turbulent flows. However, this code in its original form does not accommodate internal obstacles when applied to internal flows. The present paper discusses the modifications made to the flow solver with application to the flow analysis of Space Shuttle quick separable disconnect valves. A portion of this work is based on Ref. 10., in which detailed flapper stability boundaries are not reported.

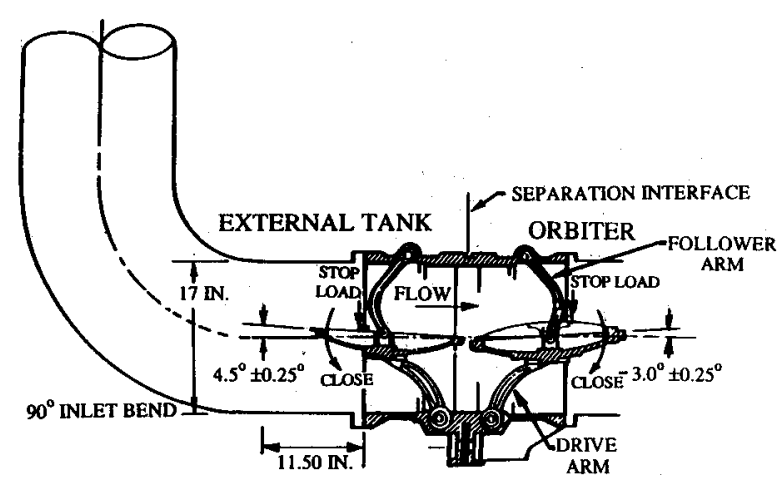

Fig. 1a Configuration of $\mathrm{LO}_{2}$ disconnect valve.

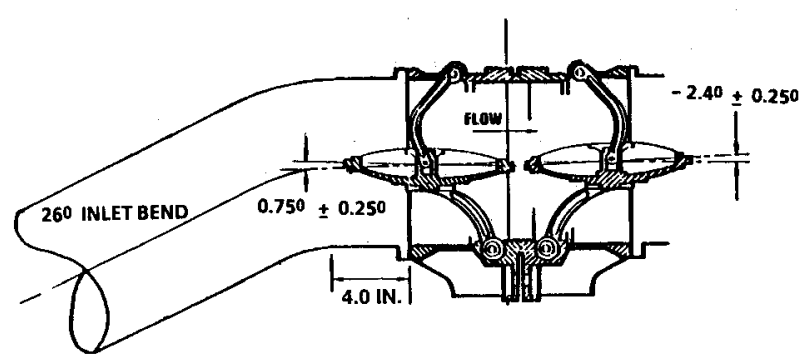

Fig. 1b Configuration of $\mathrm{LH}_{2}$ disconnect valve. 


\section{Analysis}

\section{Physical Assumptions}

Because of the complexity of the geometry and the flow characteristics, a number of simplifying assumptions have been made to achieve a practical solution. The major assumptions follow.

1) The flow is assumed to be steady.

2) Flow visualizations during water tests have indicated that, at a given flow rate, the flappers settle to a new equilibrium position about which they vibrate. In this analysis, the flappers are assumed to be stationary about their equilibrium position, and any fluid-structure interaction is ignored.

3) The linkages (drive and follower arms) are removed from consideration. Although the linkages contribute to the overall pressure drop, their modeling involves prohibitively large computing time, so that their contribution to the pressure drop can be approximately evaluated by an empirical correlation.

4) Step-like roughness at the flapper surface due to linkage joints are not taken into account. Thus, the flappers are taken as smooth surfaces. Similarly, other walls in the system are assumed smooth. The flapper curvature and flapper angle are given primary consideration.

5) The flapper edges are smoothed out, and the flapper diameters are slightly reduced from 16.3 to $15.1 \mathrm{in}$. to provide a reasonable gap for computational stability in the annular region between the flapper and the tube which is $17 \mathrm{in.}$ in diameter.

This assumption amounts to a decrease of $7 \%$ in the flapper diameter and $14 \%$ in the surface area of the flappers. Thus, the error in computing the net hydrodynamic loads due to a change in the flapper surface area is about $14 \%$. Since the pressure difference across the flapper near the leading and trailing edges are modeled fairly accurately regardless of a small decrease in flapper diameter, it is considered that the location of the neglected material (near the edge of the flapper) may not introduce additional significant error in the calculation of pitching moments. As the thickness of the flapper is small compared to the pipe diameter, the flowfield about the downstream flapper is not expected to be influenced strongly by the errors incurred in the edge clearance between it and the neighbor upstream.

6) The turbulent flow is assumed to be developed fully about 2 tube diameters upstream of the elbow. In the test setup, a straight pipe several tube diameters long is located upstream of the elbow to allow fully developed flow near the inflow.

7) The outflow boundary is taken at about 3.5 tube diameters downstream of the orbiter flapper to allow the flow to be somewhat straightened. This assumption permits simple boundary conditions to be prescribed at the outflow.

8) The system is isothermal.

\section{Governing Equations}

The details of the artificial compressibility method and numerical algorithm for three-dimensional steady incompressible viscous flow are given by Kwak et al. ${ }^{9}$ Only the major features as applied to the interior obstacles will be described in detail here.

The continuity equation is modified by the introduction of a pressure wave using an artificial equation of state,

$$
p^{\prime} / \rho^{\prime}=\beta^{\prime}
$$

where $\beta^{\prime}$ is the compressibility parameter. As a result, the governing Reynolds-averaged Navier-Stokes equations become hyperbolic and are given in dimensionless tensor notation:

$$
\begin{gathered}
\frac{1}{\beta} \frac{\partial p}{\partial t}+\frac{\partial u_{i}}{\partial x_{i}}=0 \\
\frac{\partial u_{i}}{\partial t}+\frac{\partial u_{i} u_{j}}{\partial x_{j}}=-\frac{\partial p}{\partial x_{i}}+\frac{\partial \tau_{i j}}{\partial x_{j}}
\end{gathered}
$$

where

$$
\begin{array}{ccc}
x_{i}=\frac{x_{i}^{\prime}}{x_{r}}, \quad t=\frac{t^{\prime} u_{r}}{x_{r}}, \quad u_{i}=\frac{u_{i}^{\prime}}{u_{r}}, & p=\frac{p^{\prime}-p_{r}}{\rho^{\prime} u_{r}^{2}} \\
\tau_{i j}=\frac{\tau_{i j}^{\prime}}{\rho^{\prime} u_{r}^{2}}, \quad v=\frac{v^{\prime}}{x_{r} u_{r}}=\frac{1}{R e}, & \beta=\frac{\beta^{\prime}}{\rho^{\prime} u_{r}^{2}}
\end{array}
$$

The primes denote dimensional quantities and the subscript $r$ denotes reference quantities.

\section{Difference Equation Formulation of INS3D}

In the INS3D code, the physical coordinates are transformed into generalized curvilinear coordinates:

$$
\xi_{i}=\xi_{i}\left(x_{i}, t\right)
$$

where $\xi_{i}=\xi, \eta$, or $\zeta$, and $x_{i}=x, y$, or $z$ for $i=1,2$, or 3 , respectively. The governing equations are then transformed to computational space, with the Jacobian of the transformation given by

$$
J=\operatorname{det}\left[\partial \xi_{i} / \partial x_{i}\right]
$$

Implicit approximate factorization scheme ${ }^{11,12}$ is employed. Although both fully implicit (Euler implicit, first order time accurate) and trapezoidal time differencing (second order time accurate) are considered, only Euler implicit scheme has been investigated in this work. With the smoothing terms included, the approximate factored form of the governing difference equations for fully implicit scheme in delta form become

$$
L_{\xi} L_{\eta} L_{\zeta} \Delta Q^{n+1}=f\left(Q^{n}\right)-\epsilon_{e}\left[\delta_{\xi}^{(4)}+\delta_{\eta}^{(4)}+\delta_{\xi}^{(4)}\right] Q^{n}
$$

where the solution vector $Q$, the operator $L_{\xi_{i}}$, and the residual vector $f\left(Q^{n}\right)$ are given by

$$
\begin{gathered}
Q=[p, u, v, w]^{T} \\
L_{\xi_{i}}=\left[1+\Delta t J^{n+1} \delta_{\xi_{i}}\left(A_{i}^{n}-T_{i}\right)-\epsilon_{i} \delta_{\xi_{i}}^{(2)}\right] \\
f\left(Q^{n}\right)=-\Delta t J^{n+1}\left(\delta_{\xi} E_{1}^{n}+\delta_{\eta} E_{2}^{n}+\delta_{\zeta} E_{3}^{n}\right) \\
+\Delta t J^{n+1}\left(\delta_{\xi} T_{1}+\delta_{\eta} T_{2}+\delta_{\zeta} T_{3}\right) Q^{n}-\left[I-\left(J^{n+1} / J^{n}\right)\right] Q^{n}
\end{gathered}
$$

In these equations, $A_{i}$ is the coefficient matrix, $T_{i}$ the viscous operator, $\delta_{\xi_{i}}, \delta_{\xi_{i}}^{(2)}, \delta_{\xi_{i}}^{(4)}$ the central differences of first, second, and fourth order, respectively, and $\epsilon_{i}$ and $\epsilon_{e}$ the coefficients of second-order implicit and fourth-order explicit smoothing terms, respectively.

The numerical scheme of Eq. (4) is accurate to $\theta\left(\Delta x^{2}\right)$ and $\vartheta(\Delta t)$. The previous equations reduce to a block tridiagonal matrix of the form

$$
A_{i} \Delta Q_{i-1}^{n+1}+B_{i} \Delta Q_{i}^{n+1}+C_{i} \Delta Q_{i+1}^{n+1}=D_{i}^{n}
$$

in each spatial direction and are solved for $\Delta Q$ at $n+1$ iteration using successive sweeps, where

$$
\Delta Q^{n+1}=Q^{n+1}-Q^{n}
$$

\section{Modifications to INS3D}

In its original form, the INS3D code does not allow any interior obstacles for internal flow. Therefore, the code is modified to accept interior obstacles of arbitrary geometry and tested for solution stability, convergence, and accuracy. This marks an important contribution of the present report. Following are the major modifications made.

1) The grid region corresponding to the interior obstacles is blanked out. Thus, a so-called porosity method is used for treating the flappers in the computational grid. 
2) The coefficients of the block tridiagonal matrix corresponding to the blanked grid points are set such that in Eq. (5)

$$
A_{i}=0, \quad B_{i}=1, \quad C_{i}=0, \quad D_{i}=0
$$

so that the solution at those points is not carried out.

3) Second-order explicit smoothing is considered near the surface of the internal obstacles.

4) Appropriate explicit boundary conditions are imposed on the exterior of these obstacles.

5) An under-relaxation scheme has been implemented to provide enhanced stability and accuracy of the flow solution.

\section{Flow Solution}

The adjustable parameters in the solution include the compressibility parameter $\beta$, the smoothing coefficients $\epsilon_{i}$ and $\epsilon_{e}$, and the time step $\Delta t$. The stability, convergence, and accuracy of the solution is known to depend strongly on these parameters, in addition to the quality of the given grid. In general, the choice of these parameters depends on the grid configuration and Reynolds number, and no definitive rules for setting their range currently exist. The choice is one of trial and error procedure. Even in laminar flow at low Reynolds number, the selection of these parameters is not well developed. The situation becomes more difficult at high Reynolds number and for complex geometry with interior obstacles. The present section discusses some of the guidelines reported in Ref. 9 and our observations in dealing with the present geometry.

\section{Compressibility Parameter}

The magnitude of $\beta$ controls the speed of the pressure wave and plays an important role in determining not only convergence, but also accuracy and stability. ${ }^{9} \mathrm{~A}$ criterion for the limits of $\beta$ are given in Ref. 9 for one-dimensional flow. The lower bound for $\beta$ is decided by the fact that the pressure wave propagates much faster than the spreading of vorticity. The upper bound of $\beta$ is estimated by the error associated with the addition of terms (both in continuity and momentum equations) in the approximate factorization and is given by

$$
\beta<\mathcal{O}(1 / \Delta t)
$$

Similar constraint was also noted in a paper by Steger and Kutler. ${ }^{13}$ Thus, no fundamental principle is violated by using any arbitrary value of $\beta$ as long as it satisfies the constraint.

In a given problem, some particular choice of $\beta$ ensures faster convergence, stability, and accuracy. The optimum or the best choice of $\beta$ reported in various studies is, therefore, arrived at through only numerical experimentation. An examination of the existing literature on Navier-Stokes simulations suggests that the choice of $\beta$ has a linkage to the time step, which in turn is related to the Reynolds number.

For one-dimensional and two-dimensional problems involving simple geometries and low Reynolds number (typically laminar flow), usually a value of $\Delta t=0.1$ is used, with a choice of $\beta$ in the range $1-10$, which satisfies the upper bound given by Eq. (7a). In these cases, an excellent first approximation is $\beta=1$. However, for complex geometries and/or high Reynolds number (typically turbulent flow), lower values of $\Delta t$ had to be used on stability grounds, in which case the value of $\beta$ is increased.

For example, Rogers et al. ${ }^{14}$ recently solved a system of equations in pseudocompressibility form using line relaxation technique [no approximate factorization is involved, and so maximum $\beta$ is not limited by Eq. (7a)] in a time-accurate manner. For a simple two-dimensional unsteady case, the authors used $\Delta t=0.1$ and $\beta=1.0$. However, in analyzing a three-dimensional flow in an artificial heart valve of complex geometry $\left(\operatorname{Re}=1 \times 10^{2}\right)$, they used $\Delta t=0.025$ and $\beta=500$. It is noted that in some cases the choice of $\beta$ could cause the scheme to become unstable. In yet another paper by Rogers and Kwak, ${ }^{15}$ using the above solution technique, a two-dimen- sional unsteady flow over a cylinder (involving separation and wake region with vortex shedding) at $R e=2 \times 10^{2}$ was simulated using $\Delta t=0.025$ and $\beta=2500$.

The authors independently reached similar observations in their initial checkout of INS3D code by a simulation of the hydrodynamic development in a circular tube. For low Reynolds number $\left(<1 \times 10^{3}\right)$, a value of $\Delta t=0.1$ and $\beta$ in the range $1-10$ were found to be adequate to achieve converged and stable solution. At higher Reynolds number of $10^{4}$, $\Delta t=0.01$ and $\beta=100$ were found to insure convergence and stability. The accuracy of the computed results (velocity and pressure distributions, friction factor, and development lengths) were checked with analytical results and correlations.

In the case of the disconnect valves (complex geometry, high Reynolds number, separation, wake, etc.), $\Delta t=0.002$ with $\beta=500$ ensured stable solution. The authors did try $\Delta t=0.002$ with $\beta$ starting from 1 . Values of $\beta=\mathcal{O}$ (1) did not yield stable computations. Larger values of $\beta=\mathcal{\Theta}(100)$ ensured stability with acceptable convergence in the pitching moments, although the residuals dropped only 1.5 orders of magnitude, as will be seen later in the paper. Based on the previous considerations, and to provide a consistent selection of $\beta$, a value of

$$
\beta=C / \Delta t
$$

corresponding to the upper bound is used in the present investigation, with $C=1.0$.

Large values of $\beta$ cause the ratio of absolute values of maximum and minimum eigenvalues to be large, thereby making the system of equations very stiff, which greatly reduces convergence. In the present work, choice of large $\beta$ is required on the basis of stability considerations.

\section{Time Step}

A linear von Neumann stability analysis shows that the Alternating Direction Implicit (ADI) method in delta form is known to be unconditionally unstable for three dimensions due to the extra factor for the third dimension. ${ }^{16,17}$ Consequently, the choice of time step is important to ensure stability of the solution. The local time step for stability based on the explicit scheme provides a guide and is given by the acoustic [Courant-Friedricks-Lewy (CFL) condition] and diffusion limitations, ${ }^{18}$

$$
\Delta \tau=\min \left[\frac{\Delta S}{|\boldsymbol{V} \cdot \boldsymbol{l}|+c+\left(\alpha \mu_{\mathrm{tot}} / \Delta S\right)}\right]
$$

where $l$ is the unit vector along the curvilinear arc distance $\Delta S$ and $V$ the velocity vector. The quantity $\mu_{\text {tot }}$ is the total viscosity given by

$$
\mu_{\mathrm{tot}}=\mu+\mu_{\mathrm{turb}}
$$

and $\alpha$ is the inverse of the diffusion number and is of the order of $4 .{ }^{19}$ The pseudospeed of sound $c$, for one-dimensional problems, is given by ${ }^{9}$

$$
c=\sqrt{u^{2}+\beta}
$$

For problems under investigation, $u=\mathcal{\Theta}(1)$ and, thus, $c \gg|V \cdot l|$. Furthermore, for high Reynolds number flow applications, the third term in the denominator is much smaller than $c$. As a result, for high Reynolds number, the stability is governed primarily on the compressibility parameter $\beta$.

\section{Smoothing Coefficients}

Numerical dissipation or smoothing terms are added to smooth high-frequency oscillations associated with central differencing.

The value of $\epsilon_{e}$ is scaled here with $\Delta t$ such that

$$
\epsilon_{e}=\Delta t / 2
$$


to maintain consistent definition of $\epsilon_{e}{ }^{13} \mathrm{~A}$ certain relation between $\epsilon_{e}$ and $\epsilon_{i}$ exists that maintains the stability of the solution. Based on a linear stability analysis for one-dimensional flow and numerical experimentation, a relation

$$
\epsilon_{i}=3 \epsilon_{e}
$$

has been suggested in INS3D and is employed in this analysis.

\section{Initial and Boundary Conditions}

For the initial condition, the streamwise velocity distribution is taken to be the same as that at inflow. The pressure is taken to be 1.0 throughout.

No slip boundary condition is used on all solid surfaces including the internal obstacles. The normal pressure gradient is set to zero on the walls, i.e.,

$$
\frac{\partial p}{\partial n}=0
$$

At the inflow, static pressure of 1.0 is specified and a powerlaw-type turbulent flow velocity profile for fully developed conditions is employed. All of the flow variables are extrapolated linearly at the outflow boundary. A correction for the streamwise velocity at time level $n$ is applied based on mass weighted extrapolation as ${ }^{9}$

$$
\left(u^{n}\right)_{\text {out }}=\frac{m_{\text {in }}}{\dot{m}_{\text {out }}}\left(u^{n}\right)_{\text {out }, e}
$$

where the subscript $e$ denotes extrapolated value. The quantities $\dot{m}_{\text {in }}$ and $\dot{m}_{\text {out }}$ are the mass fluxes at the inflow and outflow, respectively, with the mass flux defined by

$$
\dot{m}=\int_{A} \boldsymbol{V} \cdot \mathrm{d} \boldsymbol{A}
$$

all of the boundary conditions are treated explicitly, for the sake of convenience.

\section{Turbulence Model}

The nature of turbulent flow in the present geometry is complicated by the upstream bends and internal obstacles. Although the well-known Baldwin-Lomax model ${ }^{20}$ is widely used for external flow, its application to the present case may not be appropriate since the location of maximum moment of vorticity, taken as the turbulence length scale, is not well defined for internal flows. A simple and crude turbulence model is coded initially based on Prandtl mixing length theory for turbulent shear flow in pipes. The use of mixing length model has been extended successfully to model the Space Shuttle main engine, high-pressure fuel turbo pump turn-around duct. ${ }^{21}$ However, caution needs to be exercised in the use of mixing length turbulence models for complex flows such as those under consideration. ${ }^{22}$ Higher order $k-\epsilon$ models ${ }^{23,24}$ would improve the accuracy of the results and will be considered in a future investigation.

In the present work, the turbulent viscosity is computed based on the assumption of local fully developed pipe flow conditions. Thus, we have $\mathrm{e}^{21}$

$$
\begin{array}{ll}
\frac{\nu_{t}^{\prime}}{u^{*} R_{L}}=k^{2}\left(1-e^{-k y^{+}}\right)\left(1-y^{+}\right)^{1 / 2}, & y^{+} \leq 0.8 \\
\frac{\nu_{t}^{\prime}}{u^{*} R_{L}}=\frac{\nu_{t}^{\prime}}{u^{*} R_{L}} \quad \text { at } \quad y^{+}=0.8, & y^{+} \geq 0.8
\end{array}
$$

where

$$
y^{+}=y^{\prime} u^{* / \nu^{\prime}}, \quad u^{*}=\sqrt{\tau_{w}^{\prime} / \rho^{\prime}}
$$

In Eqs. (12), $k$ is the mixing length constant of $0.4, y^{\prime}$ the distance from the wall (pipe wall or the wall of internal obsta- cle), and $\tau_{w}^{\prime}$ the wall shear stress. The length scale $R_{L}$ is taken as the effective radius of the local flow cross section normal to the stream.

The turbulence model is conveniently coded in the transformed coordinates (Fig. 2). The region between two opposing pipe walls and that between a pipe wall and the wall of an internal obstacle is halved. At any streamwise cross section, two eddy viscosities are computed at any point in each halfregion: one based on the distance from pipe wall $y_{1}^{+}$, and the other based on the distance from an appropriate adjacent pipe wall or the wall of an internal obstacle, $y_{2}^{+}$. The lower of the two values is considered to be representative eddy viscosity.

\section{Under-Relaxation}

The boundary conditions at inflow and outflow, as discussed earlier, are more appropriate for an elliptic problem. Thus, care needs to be exercised in applying the boundary conditions rather gradually during time iterations for promoting solution stability. Such a treatment has become necessary for high Reynolds number flows with interior obstacles. Some kind of relaxation is therefore considered to preserve the stability of the solution, as suggested in Ref. 25 .

In the present study, both boundary and global under-relaxation have been found to be useful and are conveniently implemented as

$$
Q_{i}^{n+1}=Q_{i}^{n}+\alpha_{r} \Delta Q_{i}^{n+1}
$$

where $\alpha_{r}$ is an under-relaxation factor corresponding to the pressure and the three velocity components.

Typical values of $\alpha_{r}$ chosen in the present problem for $p$ and $u_{i}(i=1,2$, and 3$)$ are

$$
\begin{aligned}
\alpha_{r} & =(0.01,0.5,0.5,0.5), & & J=2 \\
& =(0.05,0.5,0.5,0.5), & & J=J_{\max }-1, \quad J_{\max }-2 \\
& =(0.8,0.5,0.5,0.5), & & J=2<J<J_{\max }-2
\end{aligned}
$$

where $J=1$ and $J=J_{\max }$ represent the inflow and outflow, respectively.

\section{Computational Grid}

An interactive grid generation code IMAGINE ${ }^{26}$ was developed that integrates INGRID ${ }^{27}$ and SVTGD3D ${ }^{27,28}$ grid generation codes and the PLOT3D ${ }^{29}$ graphics code. The code INGRID is a two-dimensional interactive grid generator, and the code SVTGD3D is a three-dimensional grid generator in batch mode. Three-dimensional grids of the disconnect are generated on a VAX 8650 machine using a combination of algebraic transfinite interpolation and elliptic smoothing from the solution of the Poisson equation. ${ }^{30}$

The computational grid of the $\mathrm{LO}_{2}$ disconnect for the coarse grid is illustrated in Fig. 3. Initial two-dimensional H-type algebraic grids are generated, using INGRID, for flow cross sections without the flappers at typical streamwise position. These grids are then smoothed by the elliptic solver using appropriate forcing coefficients and an iterative process until the grid is satisfactory in terms of orthogonality, smoothness,

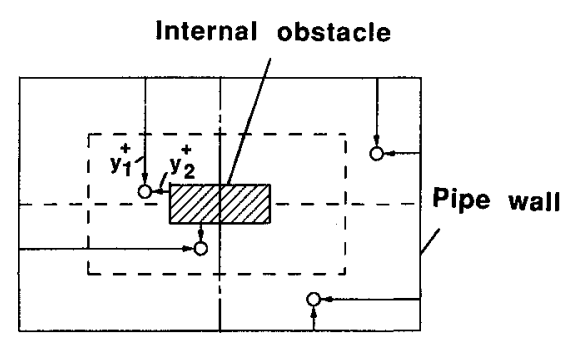

Fig. 2 Computation of turbulent viscosity. 


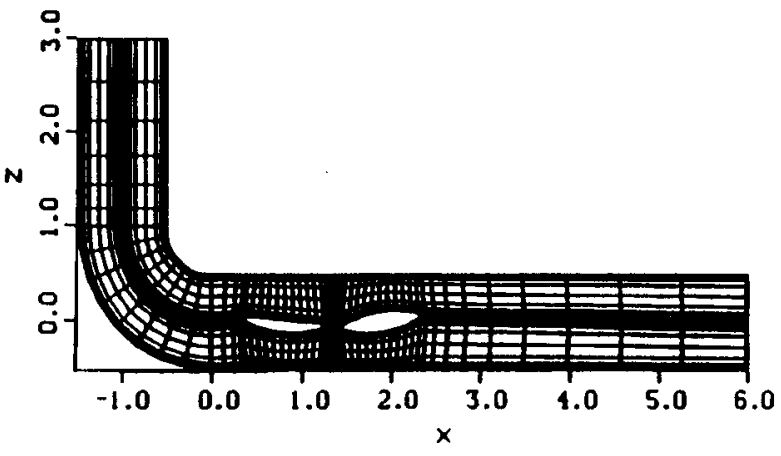

a) Side view and exit cross-sectional view of the grid
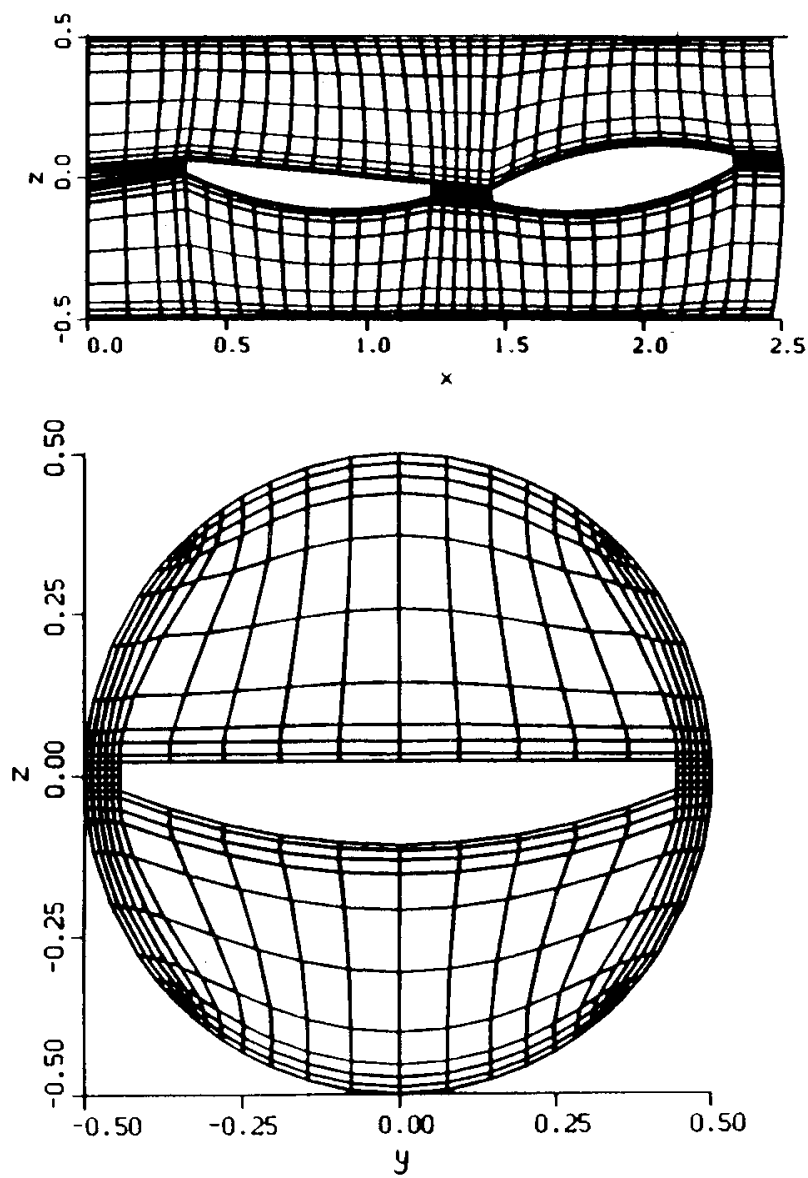

b) Detailed views of ET and orbiter flapper grids
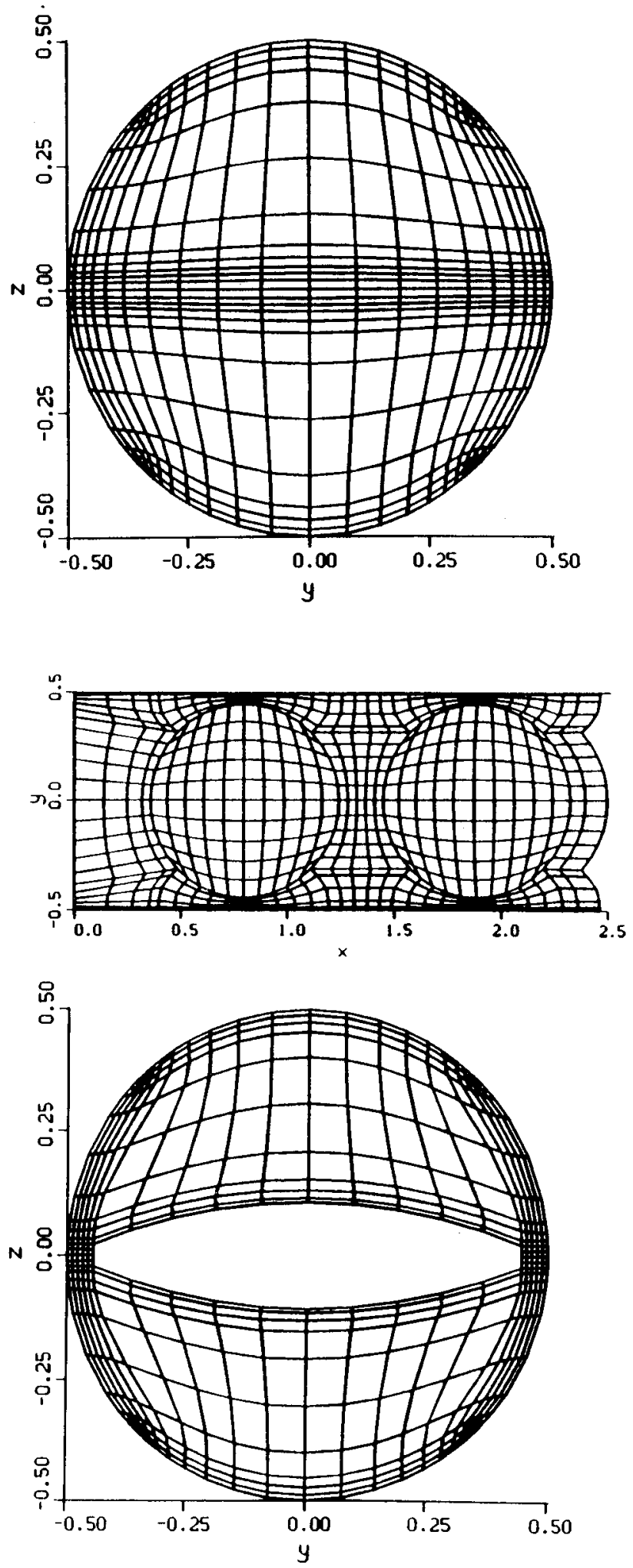

Fig. 3 Computational grid for $\mathrm{LO}_{2}$ disconnect.

and clustering. Interior flapper surfaces are then defined, and an initial three-dimensional algebraic grid is generated using SVTGD3D by a volume patching process. Cross sections containing the flappers are improved by elliptic smoothing using INGRID. The final three-dimensional algebraic grid is then generated. No elliptic smoothing was done on the three-dimensional grid.

The grid is clustered at all solid boundaries, flapper leading and trailing edges, and in the wake regions, where flow varia- tions are expected to be large. Hyperbolic tangent functions are used for grid stretching. In regions containing the flappers, cubic Bezier curves are also specified to provide grids that are more nearly orthogonal.

\section{Force and Moment Routine}

The forces and moments on the interior flappers due to pressure and viscous forces are computed by a three-dimensional generalized force/moment routine. This program is 
based on the equations derived in Ref. 31 and employs trapezoidal quadrature in the computational domain.

\section{Convergence History}

\section{Results}

The convergence of the solution is measured by the root mean squared (RMS) values of $\Delta Q$, denoted by RMSDQ. The

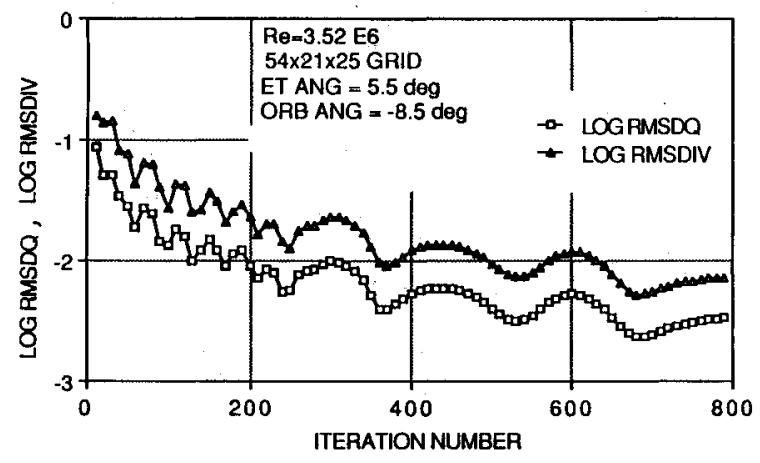

Fig. 4a Convergence history for $\mathrm{LO}_{2}$ disconnect. accuracy of the solution is monitored by the quantity RMSDIV, which is the RMS value of the divergence of the velocity field. Also the maximum value of $\Delta Q, D Q M A X$, is checked to insure stability of the solution.

Figure $4 \mathrm{a}$-presents the convergence history of the $\mathrm{LO}_{2}$ coarse grid $(54 \times 21 \times 25)$ at a full power Reynolds number of $3.52 \times 10^{6}$ and in-flight flapper angles. In these calculations, a time step of 0.002 and a $\beta$ of 500 are employed. The corre-

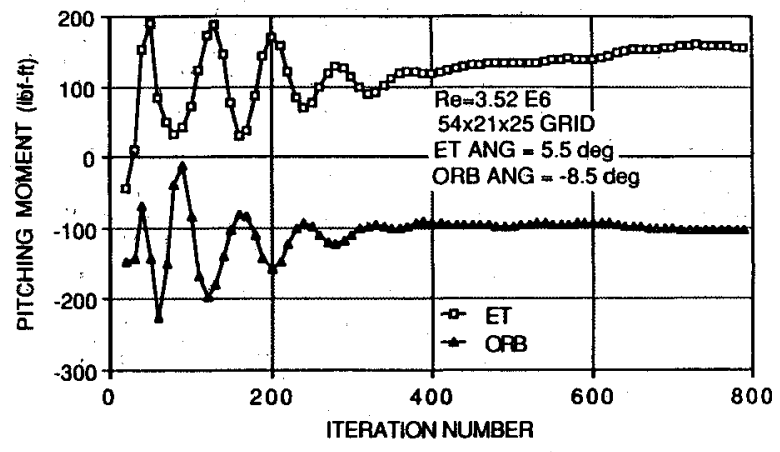

Fig. 4b Pitching moment history for $\mathrm{LO}_{2}$ disconnect.

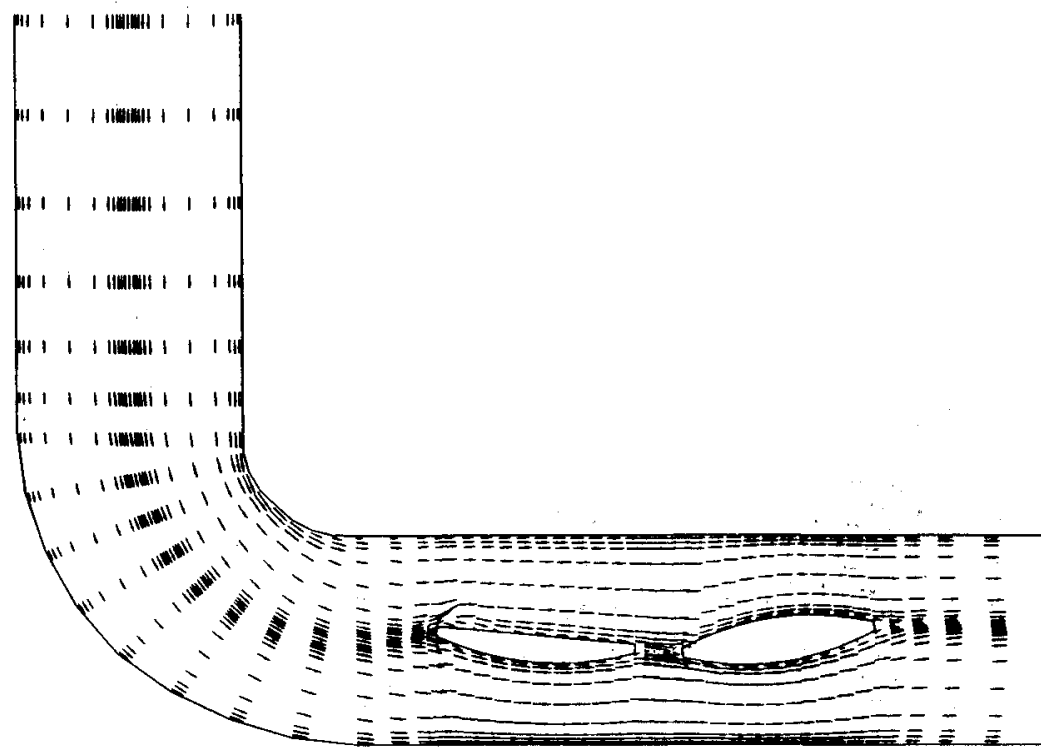

\begin{tabular}{|c|c|c|c|}
\hline$\equiv$ & $\equiv$ & $\equiv$ & $\equiv$ \\
\hline- & - & - & - \\
\hline $\overrightarrow{\underline{T}}$ & $\bar{E}$ & $\dot{\bar{n}}$ & $\overline{\overline{\underline{\underline{n}}}}$ \\
\hline- & - & - & - \\
\hline $\bar{\equiv}$ & & $=$ & \\
\hline
\end{tabular}

a) Velocity vectors

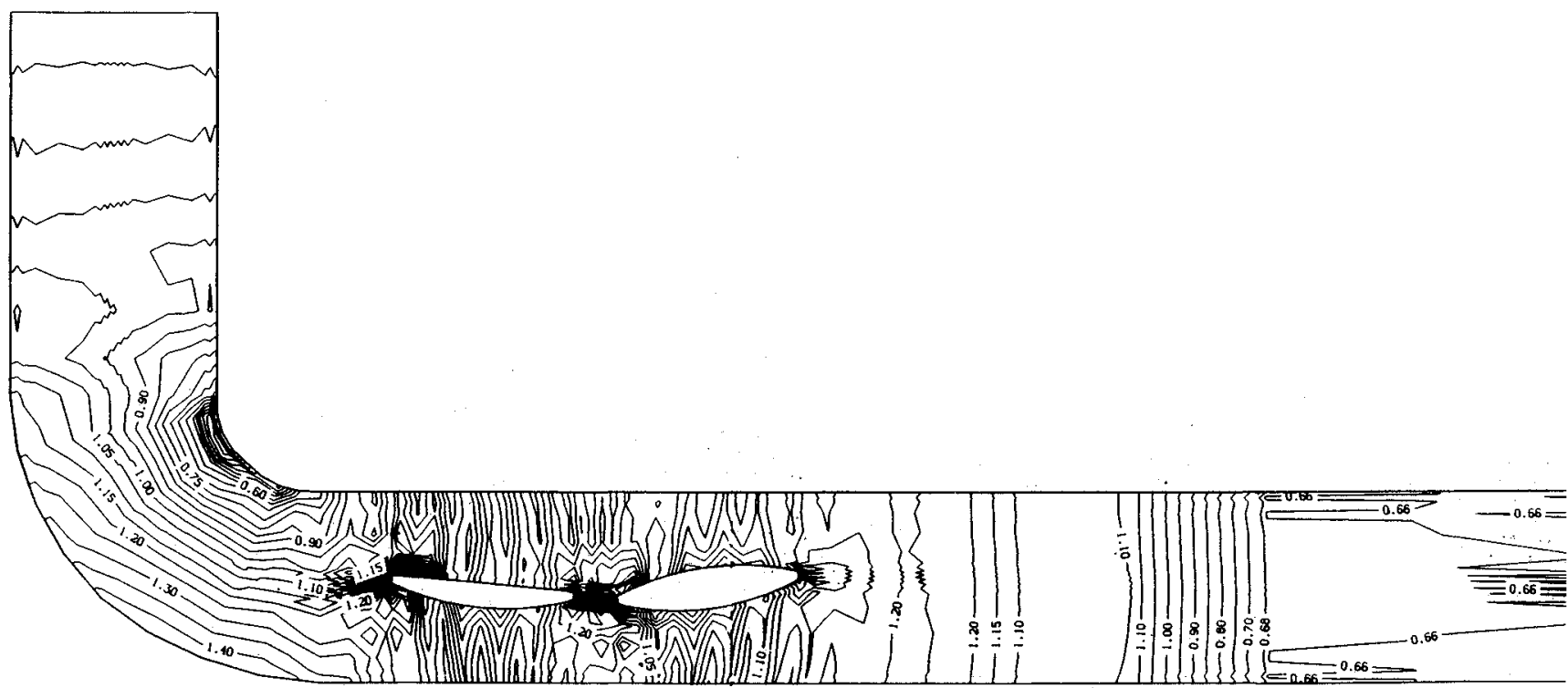

b) Pressure contours

Fig. 5 Velocity vectors and pressure contours in the $x-z$ plane for $\mathrm{LO}_{2}$ disconnect. 
sponding CFL number is about 140. It is seen that both RMSDQ and RMSDIV converge up to about 800 iterations. The convergence has decreased by only about 1.5 orders of magnitude. This relatively slow convergence is attributed to the large values of $\beta$ that are required to assure numerical stability.

The computed time-wise variation of the pitching moments for the ET and the ORB flapper is shown in Fig. 4b. The results indicate that the pitching moments on both flappers approach a nearly steady state condition for which the present solution is valid. The steady flapper pitching moments converge to within a few pound-feet, which is acceptable from a practical standpoint even though the convergence is slow. The ET flapper shows a positive pitching moment (clockwise) and the orbiter flapper a negative moment (counterclockwise). This result implies that both flappers tend to move in the open direction and are, therefore, considered stable.

Convergence for the $\mathrm{LH}_{2}$ unit at a full power Reynolds number of $2.37 \times 10^{6}$ is obtained up to 650 iterations. Again, $\Delta t=0.002(\mathrm{CFL}=90)$ and $\beta=500$ are used. The steady-state pitching moment directions show that both the flappers are stable.

Typical computing speeds are $2.8 \times 10^{-3}, 1.1 \times 10^{-4}$, and $1.5 \times 10^{-4} \mathrm{~s} / \mathrm{mesh}$ point/iteration on VAX-8650, Cray X-MP, and Cray-2, respectively. The Cray X-MP and Cray-2 super computers at NASA Marshall Research Center and NASA Ames Research Center, respectively, were linked to NASA Johnson Space Center through long distance communication lines.

\section{Flowfield}

The flow solution is visualized using the PLOT3D program. Figure 5a presents the $x-z$ view of the mean velocity vectors in the symmetry plane for $\mathrm{LO}_{2}$ disconnect at all streamwise locations. In the flow through the elbow, centrifugal forces act at right angles to the main flow and generate secondary flow. At the outer radius of the elbow, the flow decelerates initially due to an adverse pressure gradient and then begins to accelerate downstream due to a favorable pressure gradient. The situation is just the opposite near the inner radius of the bend. The point at which the velocity has its peak is shifted to the outside. Also shown are a leading-edge separation region on the ET flapper, a wake region between the flappers, and a developing turbulent wake past the orbiter flapper. Further downstream of the orbiter flapper, the flow tends to be fully developed.

Pressure contours in the $x-z$ plane of symmetry are displayed in Fig. 5b. This result shows the low and high pressure regions in the elbow, leading-edge stagnation regions, and the wake region. The isobars around the valves are not represented accurately. At the surface of the flappers, the pressure contours are not orthogonal. These factors are attributed to the coarseness of the grid and the uncertainty in the turbulence model. Similar results for the velocity vectors and pressure contours are obtained for the $\mathrm{LH}_{2}$ valve also. Pressure contours and velocity vectors in the flow cross sections containing the flappers are presented in Ref. 10, which show secondary flow, recirculation, and tip vortices near the flapper edges.

\section{Comparison of Water Test Data}

\section{Flapper Stop Loads}

The accuracy of the predicted steady-state hydrodynamic loads from the coarse grid is tested by a comparison with available water test data obtained at Wyle Laboratories in California. Rockwell International, Downey, the prime contractor for the Shuttle, subcontracted the design and development of the disconnect to Parker-Hannifin, Irvine, which monitored these tests. In the water tests, ${ }^{32}$ water at a pressure of 95 psia and a temperature of $65 \pm 15^{\circ} \mathrm{F}$ is used. A video examination of the flappers during flow suggested that the flappers settle to a new orientation during flow about which they vibrate. The incremental angle due to settling increases relatively rapidly with the flow rate up to about the minimum power level (MPL) and varies only gradually thereafter up to full power level (FPL). At full power, the ET and orbiter angles for the $\mathrm{LO}_{2}$ valve become 5.5 and $-8.5 \mathrm{deg}$, respectively, whereas their initial (no flow) angles are 4.5 and -3.5 $\mathrm{deg}$, respectively. In the present grid, the full power flow angles are used. No significant change in the flapper angles due to flow is observed for the $\mathrm{LH}_{2}$ valve.

In the test, loads are measured at two stops on each flapper, with the stops located at about 1.57 in. from the flapper center. The reaction force measured at these stops yields the pitching moment of the flapper. At no flow, there exists a load on the flapper due to the linkages. This load is given by the effective stop load at no flow, which is added to the predicted stop load from CFD analysis. Thus, the total stop load is the sum of the preload (stop load at no flow) and the hydrodynamic load.

Figure $6 \mathrm{a}$ shows a comparison of the predicted values and test data of the stop loads on the ET flapper of $\mathrm{LO}_{2}$ valve as a function of the dynamic pressure. At a given flow rate, the

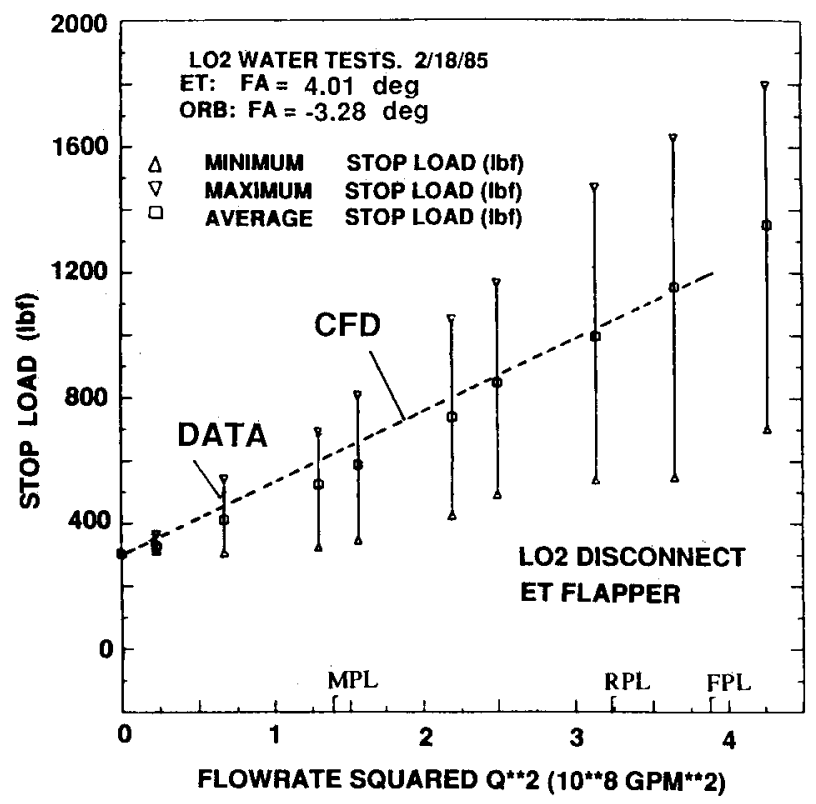

Fig. 6a Comparison of stop loads for the ET flapper of $\mathrm{LO}_{2}$ disconnect.

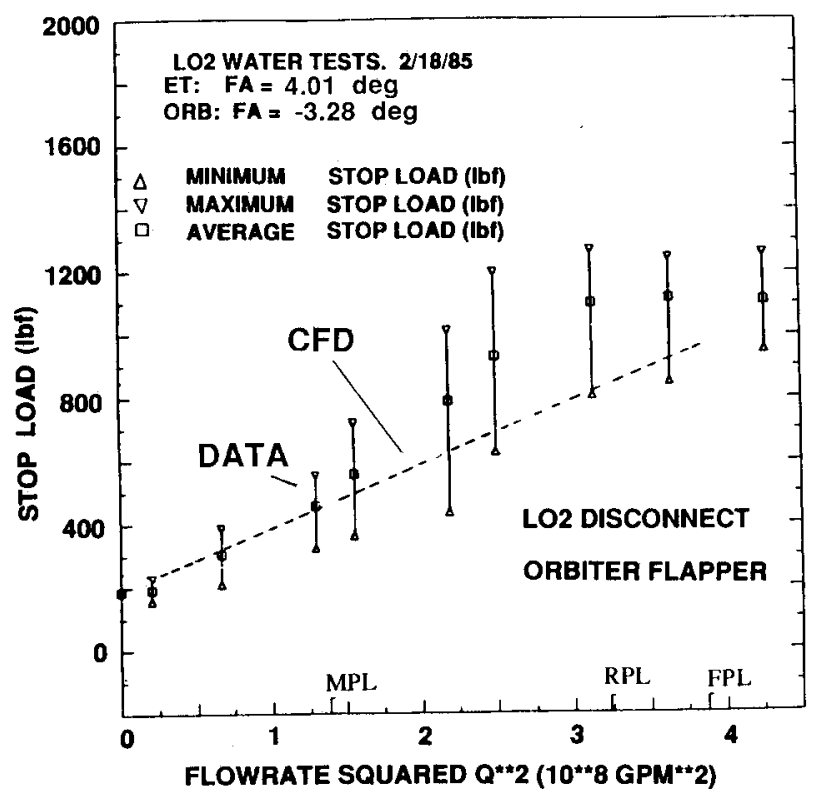

Fig. 6b Comparison of stop loads for the ORB flapper of $\mathrm{LO}_{2}$ disconnect. 


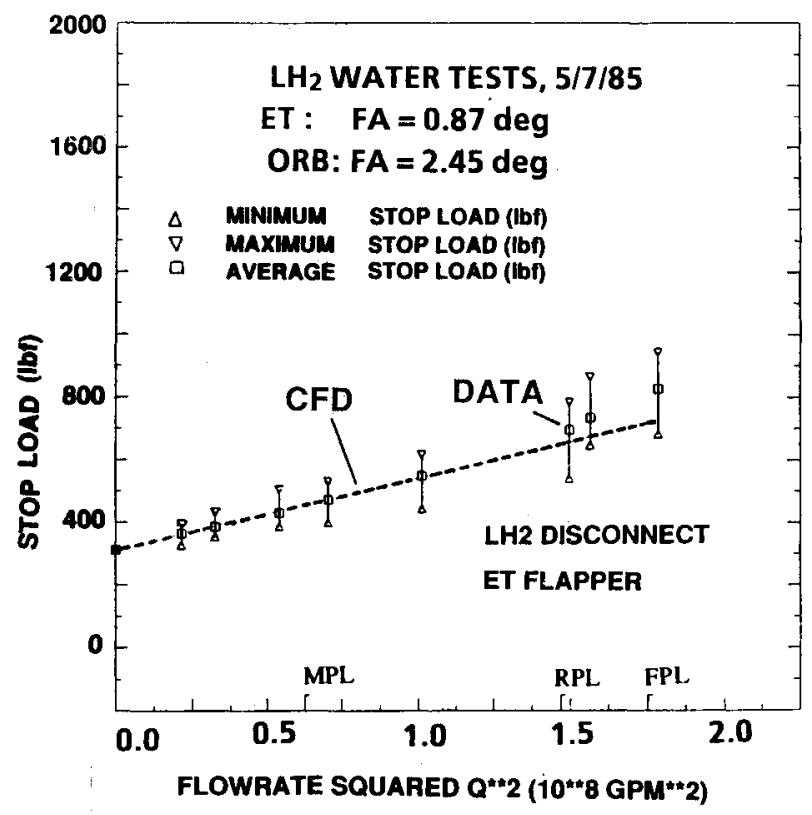

Fig. 7a Comparison of stop loads for the ET flapper of $\mathrm{LH}_{2}$ disconnect.

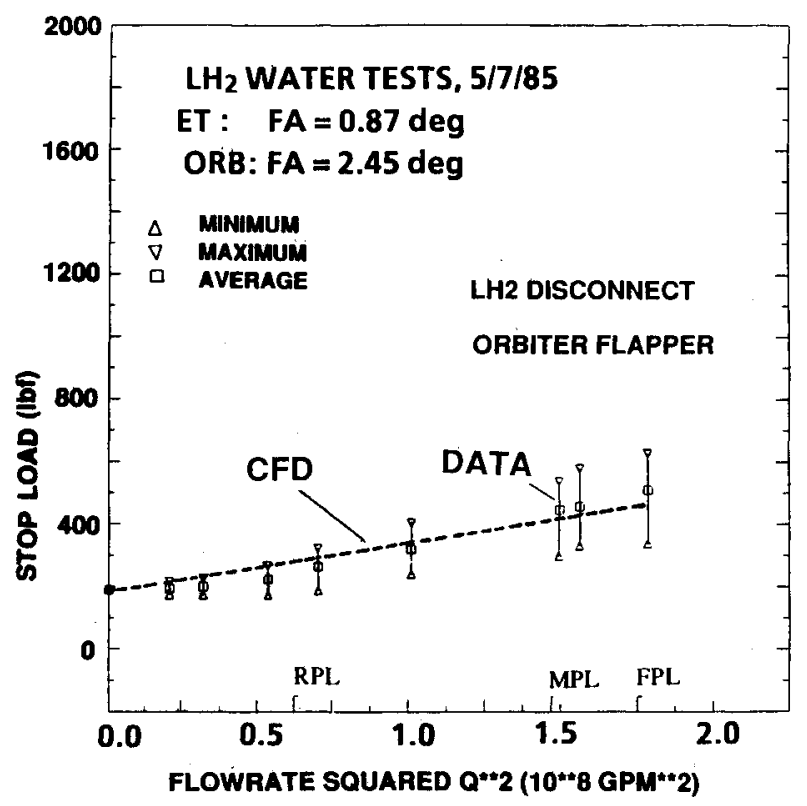

Fig. $7 b$ Comparison of stop loads for the ORB flapper of $\mathrm{LH}_{2}$ disconnect.

data show oscillations of load about an equilibrium value. These oscillations are observed to be due to flapper vibration during flow about a mean position. Therefore, the present predictions correspond to the average value of the data band at a given flow rate. The analysis is seen to predict the average stop load data satisfactorily over the flow-rate range considered. The comparisons of stop loads on the ORB flapper are displayed in Fig. 6b. The analysis predicts the data well in the low flow-rate range, but somewhat underpredicts the data in the higher flow-rate range. The evidence for flattening of the data is also suggested by marks on the flapper in a post-test examination, indicating that at the larger flow rate the ORB flapper contacts the drive arm. The inability of the model to predict the nonlinear form of the stop load vs flow rate squared prior to the flapper-drive arm contact is perhaps due to the inadequacy of the simple turbulence model.

Displayed in Figs. $7 \mathrm{a}$ and $7 \mathrm{~b}$ are the comparisons of stop loads for the $\mathrm{LH}_{2}$ ET and ORB flappers, respectively. Excellent comparison is noted between the predictions and the data.

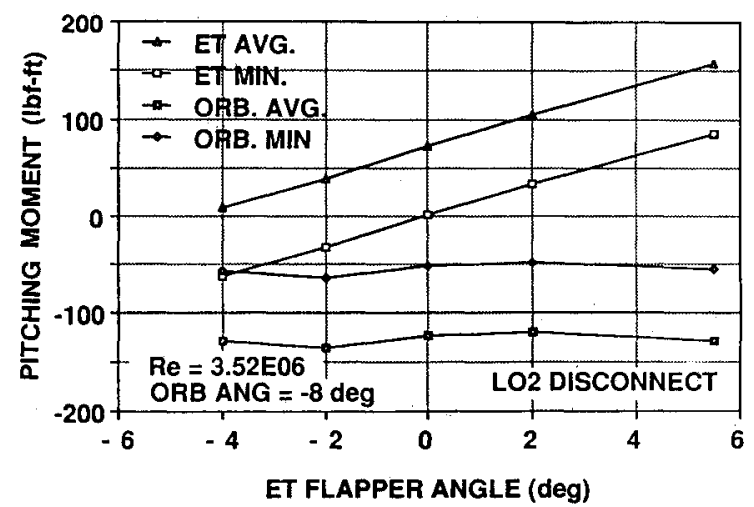

Fig. 8 Variation of flapper pitching moments with ET flapper angle of $\mathrm{LO}_{2}$ disconnect.

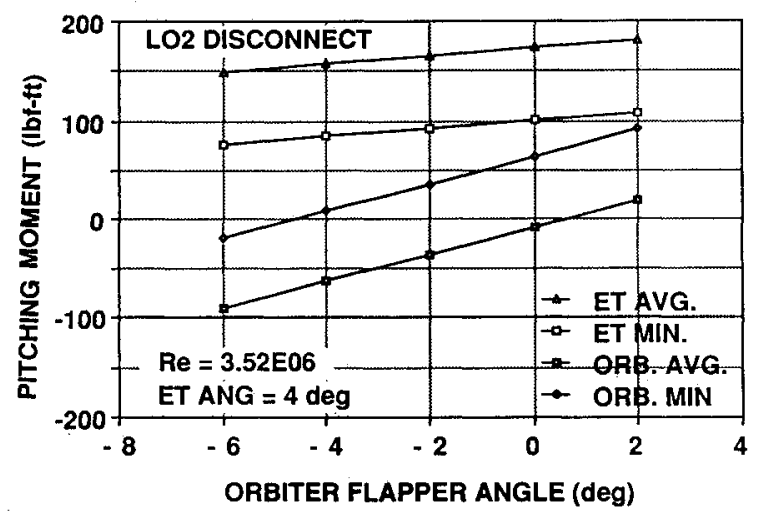

Fig. 8b Variation of flapper pitching moments with ORB flapper angle of $\mathrm{LO}_{2}$ disconnect.

\section{Pressure Drop}

Pressure drop due to flappers/linkages is measured ${ }^{33}$ by taking differential pressure data about $15 \mathrm{ft}$ upstream of the ET flapper position and $14 \mathrm{ft}$ downstream of the ORB flapper position. The measurements are taken with and without flappers/linkages and allow pressure recovery. In the analysis, pressure drop between inflow and outflow are predicted with and without the flappers. For $\mathrm{LO}_{2}$ valve, the pressure drop due to the flappers at full power $R e=3.52 \times 10^{6}$ is estimated at about 3.1 psi. This result compares to the test data of about 4.1 psi. The underprediction of pressure drop is attributed to factors including the neglect of the drive/follower arms, the assumption of smooth walls, the coarseness of the grid, and the crudeness of the turbulence model.

In the case of the $\mathrm{LH}_{2}$ valve, the computed pressure drop is about 1.7 psi, which compares with a measured value of about 1.8 psi.

\section{Flapper Stability Boundaries}

The limiting hydrodynamic stabilty of the flappers is controlled by the minimum stop loads on the flappers approaching zero at full power. Since the present model calculates only average pitching moments at steady state, minimum values of stop loads are deduced by subtracting the half-oscillation from the CFD prediction, which include the preload. Test data suggest that, for a given disconnect unit, the load oscillation varies as a cube of the flow rate, but is only weakly dependent on the flapper angles for both the flappers. The relatively low oscillation of the $\mathrm{LO}_{2}$ ORB flapper loads near full power is an exception and is attributed to the contact of the flapper with the drive arm, which was also responsible for the flattening of the data, as discussed earlier.

In the stability tests of $\mathrm{LO}_{2}$ valve, the ET flapper angles (no flow) range from 1.59 to $5.71 \mathrm{deg}$ and the ORB flapper angles range from -0.9 to $-5.33 \mathrm{deg}$. For $\mathrm{LH}_{2}$ unit, the ET flapper 
angles vary from -3.86 to $2.45 \mathrm{deg}$, and the ORB flapper angles vary from 0.86 to $-4.5 \mathrm{deg}$. Average flapper stop load oscillations of about $1100 \mathrm{lbf}$ and $300 \mathrm{lbf}$ are noted at full power for $\mathrm{LO}_{2}$ and $\mathrm{LH}_{2}$ disconnects, respectively. Both the preload and the flapper load oscillations are converted to the equivalent pitching moments.

Figure 8a displays for the $\mathrm{LO}_{2}$ unit the variation of flapper pitching moments as a function of ET flapper angle, with the orbiter flapper angle fixed near the flight angle. Both the aver-

\section{Test}

$\Delta$ Both flappers stable

$\triangle$ BT flapper unstable Stability boundary Flight envelope

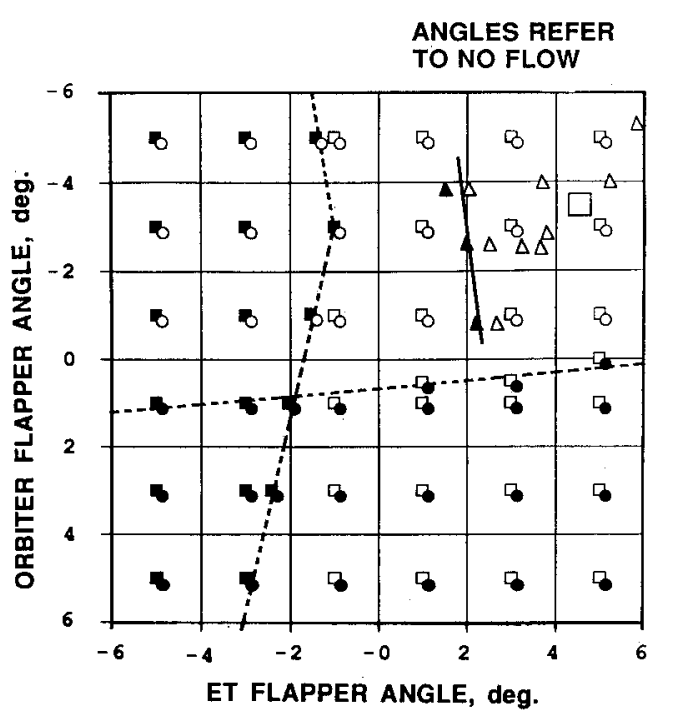

Fig. 9 Comparison of stability boundaries for $\mathrm{LO}_{2}$ disconnect.

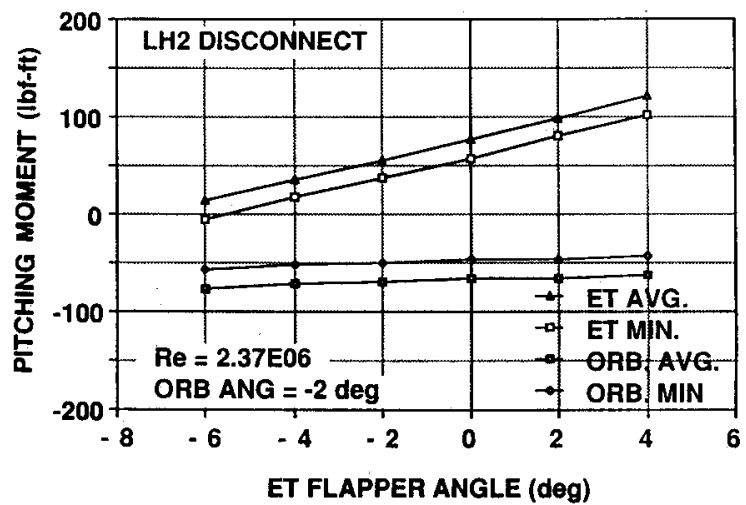

Fig. 10a Variation of flapper pitching moments with ET flapper angle of $\mathrm{LH}_{2}$ disconnect.

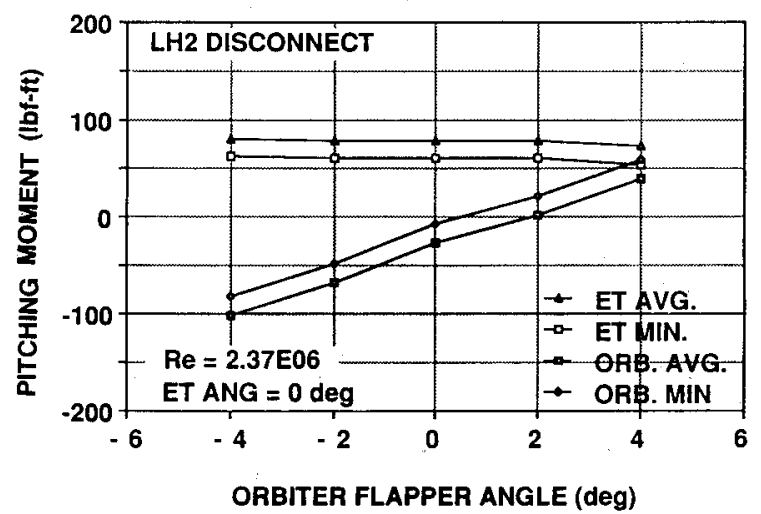

Fig. 10b Variation of flapper pitching moments with ORB flapper angle of $\mathrm{LH}_{2}$ disconnect. age and minimum pitching moments are presented for the ET flapper. As the ET flapper angle is reduced, its pitching moment decreases and changes direction at about $0 \mathrm{deg}$, which indicates the onset of instability at the given orbiter angle. However, the orbiter flapper pitching moment variation with the ET flapper angle is only slight. Calculations are repeated for various orbiter angles at a constant ET flapper angle. The orbiter flapper stability is illustrated in Fig. 8b, where the ET flapper is fixed and the ORB flapper angle is varied. When the ORB flapper is reduced to about $-4 \mathrm{deg}$, the ORB flapper pitching moment changes direction, whereas the ET flapper moment varies only weakly with the ORB flapper angle. Test data confirm these trends.

A comparison of CFD prediction and data on the stability boundaries of $\mathrm{LO}_{2}$ flappers is shown in Fig. 9. For convenience, the results are presented in terms of no-flow angles. The predicted stability boundaries for the ET flapper is within $3 \mathrm{deg}$ of the test data that are accurate to about $2 \mathrm{deg}$. The predictions determine the stability boundary of the ORB flapper; however, the test data do not extend to the stability limit.

Variations of the $\mathrm{LH}_{2}$ flapper pitching moments with flapper angles are depicted in Fig. 10. Similar trends of the flapper moments are noted, as in the case of $\mathrm{LO}_{2}$ disconnect. Figure 11 suggests a satisfactory comparison of the predicted stability limits with the test data. The ORB flapper stability line is predicted to within $1 \mathrm{deg}$, whereas the ET flapper stability is computed to within 2 deg of the test data. The relatively better correlation of stability boundaries for $\mathrm{LH}_{2}$ flappers is attributed to less uncertainty in the flapper flow angles and reduced flapper oscillations than in the case of the $\mathrm{LO}_{2}$ valve. These comparisons thus serve to validate the CFD model and demonstrate its usefulness, despite a number of physical assumptions and simplifications made in analysis.

\section{Discussion}

The primary advantage of relaxation in the present problem is to ensure and enhance stability especially due to inflow/outflow boundary conditions in high Reynolds number flows. Specifying both pressure and velocity at the upstream end is an overspecification to a hyperbolic system. As noted earlier, this boundary condition is appropriate for an elliptic problem that is approached only in steady state. Since we are seeking a steady-state solution, the boundary relaxation technique served to alleviate the problem due to overspecification and

\section{Test}

$\triangle$ Both flappers stable Orb. flapper unstable Stability boundary Flight envelope
CFD

口 ET flapper stable

- ET flapper unstable

- Orb. flapper stable

- Orb. flapper unstable

-..- Stability boundary

ANGLES REFER

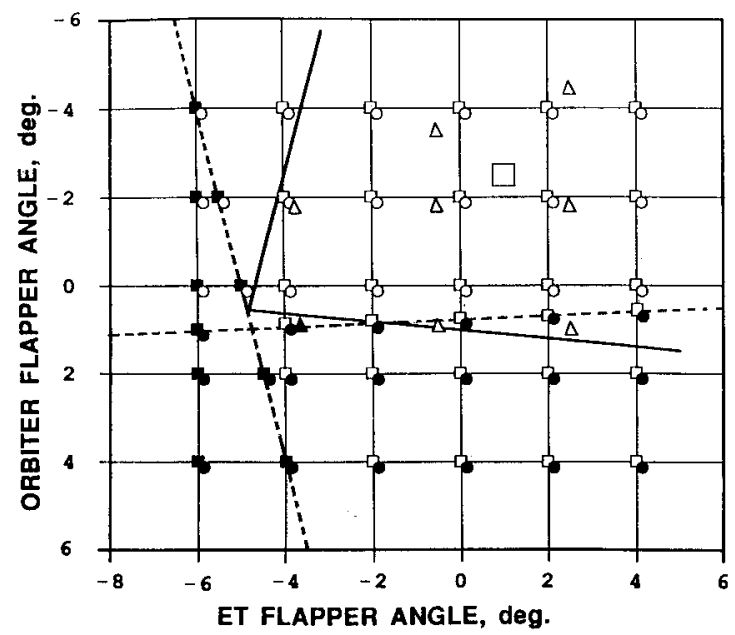
TO NO FLOW

Fig. 11 Comparison of stability boundaries for $\mathrm{LH}_{2}$ disconnect. 
produced converged solution. The overshoot in pressure at the station next to (downstream of) the inlet, which occurs due to the inconsistency in the boundary condition, is also effectively minimized to an acceptable value. Problems of stabilty at the outflow boundary, caused primarily by the secondary flow, are also satisfactorily resolved by the application of boundary relaxation.

The relatively large values of CFL used in the present work (140 for $\mathrm{LO}_{2}$ disconnect and 90 for $\mathrm{LH}_{2}$ disconnect) are made possible by the use of global relaxation technique. In the absence of relaxation, the maximum CFL number for a given grid is reduced and depends, in general, on the number of spatial dimensions of the ADI scheme, the complexity of the geometry, and Reynolds number. For example, Rai ${ }^{34}$ reported values of $\mathrm{CFL}=250$ in a two-dimensional Navier-Stokes simulation of rotor/stator interaction. Values of CFL $>500$ produced unstable results. Pan and Lomax ${ }^{17}$ reported a value of $\mathrm{CFL}=15$ for a three-dimensional case.

In some preliminary attempts to accelerate convergence using local time steping, the authors found that the technique is not helpful. It appears that in the artificial compressibility formulation large values of local time $\Delta t$ require that $\beta$ needs to be reduced in those regions, as indicated by Eqs. (7). Thus, local time stepping in conjunction with a constant value of $\beta$ may not promote convergence and stability. It is believed that implicit treatment of boundary conditions and the multigrid method could enhance convergence rate, but it is beyond the scope of the present work.

The accuracy of the predictions can be improved by the application of a higher-order turbulence model to describe better the effective viscosity under complex flow conditions present in the valve. The use of a finer grid, especially around the flappers, would improve the predictions and resolve the flowfield at flight Reynolds number of about 20 and $50 \times 10^{6}$ for $\mathrm{LO}_{2}$ and $\mathrm{LH}_{2}$ disconnects, respectively.

\section{Conclusions}

The stability, convergence, and accuracy of the modified INS3D code using a coarse grid are tested by a comparison with available water test data for hydrodynamic loads on the flappers. Satisfactory prediction of the hydrodynamic stability of the flappers is demonstrated. Complex flowfield, especially around the flappers, is observed. Although the preliminary results from the code are promising, the convergence of the code needs to be accelerated while maintaining the solution stability.

\section{Acknowledgments}

This work was supported by NASA Johnson Space Center under Contract NAS9-17900, monitored by P. E. Cota Jr., B. J. Rosenbaum, and J. D. Norris of the Propulsion and Power Division. Richard A. Colonna of the Space Transportation Systems' Orbiter and Government Furnished Equipment Projects office initiated this work. The authors thank D. Kwak and U. Kaul of NASA Ames Research Center for their helpful discussion and suggestions in the development of this program. Thanks are due to F. W. Martin Jr., of the Aeroscience Branch in the Navigation, Control and Aeronautics Division at NASA Johnson Space Center for his many useful discussions and his help in the IRIS graphics support and Cray-2 communications. The National Aerodynamic Simulation Facility at NASA Ames Research Center allocated Cray-2 computing time. NASA Marshall Space Flight Center permitted access to the Cray X-MP facility. Lockheed personnel, G. W. Adams Jr., and S. A. Trudan provided help in the preparation of this report.

\section{References}

${ }^{1}$ Pulliam T. H., and Steger, J. L.. "Implicit Finite-Difference Simulations of Three-Dimensional Compressible Flow," AIAA Journal, Vol. 18, No. 2, 1980, pp. 159-167.

${ }^{2}$ Shang, J. S., Buning, P. G., Hankey, W. L., and Wirth, M. C.,
"Performance of a Vectorized Three-Dimensional Navier-Stokes Code on the CRAY-1 Computer," AIAA Journal, Vol. 18, No. 9 , 1980, pp. 1073-1079.

${ }^{3}$ Harlow, F. H., and Welch, J. E., "Numerical Calculation of Time Dependent Viscous Incompressible Flow with Free Surface," Physics of Fluids, Vol. 8, No. 12, Dec. 1965, pp. 2182-2189.

${ }^{4}$ Dennis, S. C. R., Ingham, D. B., and Cook, R. N., 'Finite Difference Methods for Calculating Steady Incompressible Flows in ThreeDimensions," Journal of Computational Physics, Vol. 33, 1979, pp. 325-339.

5Osswald, G. A., Ghia, K. N., and Ghia, U., "A Direct Algorithm for Solution of Incompressible Three-Dimensional Unsteady NavierStokes Equations," AIAA Paper 87-1139, June 1987.

${ }^{6}$ Patankar, S. V., and Spalding, D. B., "A Calculation Procedure for Heat, Mass and Momentum Transfer in Three-Dimensional Parabolic Flows," International Journal of Heat Mass Transfer, Vol. 15, 1972, pp. 1787-1806.

${ }^{7}$ Chorin, A. J., "A Numerical Method for Solving Incompressible Viscous Flow Problems," Journal of Computational Physics, Vol. 2, 1967 , pp. 12-26.

${ }^{8}$ Choi, D., and Merkle, C. L., "Application of Time-Iterative Schemes to Incompressible Flow," AIAA Journal, Vol. 23, No. 10 , 1985 , pp. 1518-1524.

${ }^{9}$ Kwak, D., Chang, J. L. C., Shanks, S. P., and Chakravarthy, S. R., "A Three-Dimensional Incompressible Navier-Stokes Flow Solver Using Primitive Variables," AIAA Journal, Vol. 24, No. 3, 1986, pp. 390-396

${ }^{10}$ Kandula, M., and Pearce, D., "Flow Analysis of Space Shuttle Feed Line 17-Inch Disconnect Valve," AIAA Paper 88-3788, July 1988.

${ }^{11}$ Beam, R. M., and Warming, R. F., "An Implicit Finite-Difference Algorithm for Hyperbolic Systems in Conservation-Law Form," Journal of Computational Physics, Vol. 22, Sept. 1976, pp. 87-110.

${ }^{12}$ Anderson, D. A., Tannehill, J. C., and Pletcher, R. H., Computational Fluid Mechanics and Heat Transfer, Hemisphere, New York, 1984.

${ }^{13}$ Steger, J. L., and Kutler, P., "Implicit Finite-Difference Procedures for the Compuation of Vortex Wakes," AIAA Journal, Vol. 15 No. 4, 1977, pp. 581-590.

${ }^{14}$ Rogers, S. E., Kwak, D., and Kiris, C., "Numerical Solution of the Incompressible Navier-Stokes Equations for Steady-State and Time-Dependent Problems," AIAA Paper 89-0463, Jan. 1989.

${ }^{15}$ Rogers, S. E., and Kwak, D., "An Upwind Differencing Scheme for the Time-Accurate Incompressible Navier-Stokes Equations," AIAA Paper 88-2583, June 1988.

16 Jameson, A., and Yoon, S., "Lower-Upper Schemes with Multiple Grids for the Euler Equations," AIAA Journal, Vol. 25, No. 7 July 1987 , pp. 929-935.

${ }^{17}$ Pan, D., and Lomax, H., "A New Approximate LU Factorization Scheme for the Reynolds-Averaged Navier-Stokes Equations," AIAA Journal, Vol. 26, No. 2, 1988, pp. 163-171.

${ }^{18}$ Richtmyer, R. D., and Morton, K. W., Difference Methods for Initial Value Problems, Wiley, New York, 1967.

${ }^{19}$ Davis, R. L., Ni, R. H., and Carter, J. E., "Cascade Viscous Flow Analysis Using Navier-Stokes Equations," Journal of Propulsion and Power, Vol. 3, No. 5, 1987, pp. 406-414.

${ }^{20}$ Baldwin, B. S., and Lomax, H., "Thin Layer Approximation and Algebraic Model for Separated Turbulent Flows," AIAA Paper 78 257, Jan. 1978.

${ }^{21}$ Chang, J. L. C., Kwak, D., Dao, S. C., and Rosen, R., "A Three-Dimensional Incompressible Flow Simulation Method and Its Application to the Space Shuttle Main Engine, Part II-Turbulent Flow," AIAA Paper 85-1670, July 1985.

${ }^{22}$ Launder, B. E., and Spalding, D. B., Mathematical Models of Turbulence, Academic Press, New York, 1972.

${ }^{23}$ Kaul, U., and Kwak, D., "Computations of Internal Turbulent Flow with Large Separated and Secondary Flow Regions," AIAA Paper 85-1687, July 1985.

${ }^{24}$ Kaul, U. K., "An Implicit Finite-Difference Code for a TwoEquation Turbulence Model for Three Dimensional Flows," NASA TM-86752, June 1985 .

${ }^{25}$ Patankar, S. W., Numerical Heat Transfer and Fluid Flow, Hemisphere, New York, 1980.

${ }^{26}$ Kandula, M., and Pearce, D., "Computational Fluid Dynamics Analysis of Space Shuttle Main Propulsion Feed Line 17-Inch Disconnect Valves,"' Lockheed Engineering and Sciences Co., Houston, TX, Rept. 26227, Oct. 1988.

${ }^{27}$ Soni, B. K., "Two- and Three-Dimensional Grid Generation for Internal Flow Applications of Computational Fluid Dynamics," AIAA Paper 85-1526, July 1985. 
${ }^{28}$ Soni, B. K., McClure, M. D., and Heikkinen, B. D., User's Guide for SVTGD3D, Sverdrup Technology, Inc., Cleveland, OH, Sept. 1986.

${ }^{29}$ Buning, P., PLOT3D Graphics Program, NASA Ames Research Center, Moffett Field, CA, 1986.

${ }^{30}$ Thompson, J., Warsi, Z. U. A., and Mastin, C. W., Numerical Grid Generation-Foundations and Applications, Elsevier, New York, 1985.

${ }^{31}$ Kaul, V., and Chausse, D., "AFWAL Parabolized Navier-Stokes Code: 1983 AFWAL/NASA Merged Baseline Version," Air Force Wright Aeronautical Laboratory, Wright Patterson Air Force Base,
OH, Rept. TR/83/3118, May 1984

32Jones, D. L., "17-Inch Disconnect Preload Margin Development Test Program," Rockwell International, Doc. MCR 10473 R5, Downey, CA, Oct. 1985.

${ }^{33}$ Farner, D., Buchanan, M. C., Kandula, M., and Adams, W. J., “Main Propulsion Subsystem 17-Inch Disconnect Handbook," Lockheed Engineering and Management Services Company, Houston, TX, Rept. 23626, June 1988.

${ }^{34}$ Rai, M. M., "Navier-Stokes Simulations of Rotor/Stator Interaction Using Patched and Overlaid Grids," Journal of Propulsion and Power, Vol. 3, No. 5, 1987, pp. 387-396.

\title{
Dynamics of Flames and Reactive Systems and Dynamics of Shock Waves, Explosions, and Detonations
}

\author{
J. R. Bowen, N. Manson, A. K. Oppenheim, and R. I. Soloukhin, editors
}

The dynamics of explosions is concerned principally with the interrelationship between the rate processes of energy deposition in a compressible medium and its concurrent nonsteady flow as it occurs typically in explosion phenomena. Dynamics of reactive systems is a broader term referring to the processes of coupling between the dynamics of fluid flow and molecular transformations in reactive media occurring in any combustion system. Dynamics of Flames and Reactive Systems covers premixed fiames, diffusion fiames, turbulent combustion, constant volume combustion, spray combustion nonequilibrium flows, and combustion diagnostics. Dynamics of Shock Waves, Explosions and Detonations covers detonations in gaseous mixtures, detonations in two-phase systems, condensed explosives, explosions and interactions.

Dynamics of Flames and Reactive Systems 1985766 pp. illus., Hardback

ISBN 0-915928-92-2

AlAA Members $\$ 59.95$

Nonmembers $\$ 92.95$

Order Number V-95
Dynamics of Shock Waves, Explosions and Detonations 1985595 pp., illus. Hardback ISBN 0-915928-91-4

AIAA Members $\$ 54.95$ Nonmembers $\$ 86.95$ Order Number V-94

TO ORDER: Write, Phone or FAX: American Institute of Aeronautics and Astronautics, c/o TASCO, 9 Jay Gould C.., P.O. Box 753, Waldorf, MD 20604 Phone (301) 645-5643, Dept. 415 FAX (301) 843-0159

Sales Tax: CA residents, $7 \%$; DC, $6 \%$. Add $\$ 4.75$ for shipping and handling of 1 to 4 books (Call for rates on higher quantities). Orders under $\$ 50.00$ must be prepaid. Foreign orders must be prepaid. Please allow 4 weeks for delivery. Prices are subject to change without notice. Returns will be accepted within 15 days. 